\title{
EFFECT OF GLOBALIZATION ON SMALL AND MEDIUM ENTERPRISES (SMES) PERFORMANCE IN NIGERIA
}

\author{
Moruff Sanjo OLADIMEJI', Augusta Thereza, EBODAGHE², Peter Babatunde \\ SHOBAYO \\ Olabisi Onabanjo University
}

\begin{abstract}
This paper studies the effect of globalization on small and medium enterprises (SMEs) performance in Nigeria. The study adopts an ex post-facto type of descriptive research design. In carrying out this study, the secondary statistics data was used. Data was extracted from CBN bulletin on relevant information which depicts globalization and its effect on SMEs performance in Nigeria.A co-integration model was used to investigate the effect of globalization on SMEs performance in Nigeria. To capture the activities of globalization, three proxies were used to capture the activities of globalization; they include interest rate, bank credit and trade openness while on the other hand, output of SMEs to GDP was used to capture SMEs performance covering the period of 1992 to 2014. It was observed that interest rate, bank credit and trade openness do not improve the performance of SMEs output. The overall effect as shown by the F-statistics reveals that the variables considered in this study are not significant in explaining the level of improvement in SMEs output and performance in Nigeria.
\end{abstract}

\section{KEYWORDS}

Globalization, SMEs, Bank credit, Trade openness, and Interest rate.

\section{INTRODUCTION}

Today's business environment is extremely dynamic and experiencing rapid changes as a result of technological improvement, increased awareness and demands of electronic trade concept of globalization. Globalization could be defined in simple terms as the easy access or reach of a certain resource the world over. In this context, globalization is a way of removing trade barriers. Globalization is a phenomenon that no development agenda can afford to ignore. The economic activities are saturated with globalization process and the driving force of his process in small scale business.

Small scale businesses are the backbone of the nations and they consist of the largest section of businesses in most economies as well as frequently offer the greatest potential for job creation (Adeleke, 2003). SMEs can be defined based on certain criteriawhich include, turnover, number of employees, profit, capital employed, market share, asset value and relative size within the industry.

\footnotetext{
${ }^{1}$ Corresponding address: Department of Business Administration, Faculty of Social \& Management Sciences, Olabisi Onabanjo University, Ago - Iwoye, Ogun State, Nigeria. Email: sanjolanre4life@yahoo.com

${ }^{2}$ Corresponding address: Department of Business Administration, Faculty of Social \& Management Sciences, Olabisi Onabanjo University, Ago - Iwoye, Ogun State, Nigeria.

${ }^{3}$ Corresponding address: Department of Business Administration, Faculty of Social \& Management Sciences, Olabisi Onabanjo University, Ago - Iwoye, Ogun State, Nigeria. Email: shobayopeterbabatunde@gmail.com
} 
One of the major focuses on small scale businesses is that these enterprises make remarkable contributions to the economies of both developing and developed countries.

According to Usman (2001), the development of small and medium enterprises must be seen as an attempt towards the achievement of a wider economic and socio-economic objective, as well as poverty alleviation. The enterprise also drives the country's development as they create employment and contribute to the gross domestic product (GDP). Small and medium scale enterprises are expected to facilitate the growth and development of human and capital resources towards general economic development and the rural sector in particular. In view of these expected roles from SMEs, the Nigerian Government had in the past devised policies and incentives for the development of small and medium scale enterprises.

According to Adewuyi (2011), globalization is the process of opening up of economies to the outside world to aid trade, fall in physical and other barriers to enhance mobility of goods and factors of production as well as labour force. With the removal of barriers to trade, competition has intensified and has presented both opportunity and challenges to domestic firms to innovate and improve their competitive position.

The act of small and medium scale enterprises (SMEs) in the post trade liberation era in developing countries has fascinated the attention of scholars, nevertheless, their interest has been on financial, output, export, and marketing performance of firm in Nigeria, SMEs are beset with a countless of challenges on the strength of internet facilities and information technology which are in no small measure affecting their growth, the most distinct is defective infrastructure, in particular electricity and use of obsolete equipment and methods of production because of owner's inability to access new technology (Adewuyi, 2004).

However in most developing economies like Nigeria, ICT lacks the necessary infrastructure to support it. Many studies have been done on globalization relating to small scale businesses especially in developed countries. Surprisingly, reviewed literatures show that many scholars in Nigeria have expressed interest in examining the conceptual issues of globalization as it affects Africa in general and Nigeria in particular. Interestingly, few attempts have been made in empirically relating globalization to small scale business performance. Therefore, there is need to examine the effects of globalization on the performance of small scale businesses in Nigeria in order to fill the gap in knowledge.

In light of the above statement, the broad objective of this study is thus to examine the effect of globalization on small and medium scale business performance in Nigeria, while the specific objectives are; to ascertain the factors that affect SMEs development in Nigeria; examine the trend of trade openness in Nigeria on performance of SMEs development in Nigeria; and to examine the impact of bank credit on the performance of SME's in Nigeria.This research is significant because it provide answers to factors militating against the improvement of advance information technology, trade openness and also proved the success and growth associated with implementation of exportation and importation in the areas of SMEs operations that can be enhanced.

\section{LITERATURE REVIEW}

\subsection{Concept of Globalization}

Globalization is the spread of economic innovation around the world and the political and cultural adjustments that accompanies this diffusion (Hitt, Ireland \&Hoskisson, 2001). Tendon (1998) viewed globalization as the interconnectedness of contemporary civilization, which includes political, social and cultural systems. According to Sonia and Rajeev (2009) globalization is the 
process of integrating various economies of the world without creating any hindrances in the free flow of goods and services, technology, capital and even labor or human capital.

Globalization could be seen as the process of increasing interconnectedness between societies so that event in one part of the world has an effect on people and societies far away. With the concept of globalization, individual firms and corporate organizations has been able to transact businesses worldwide without restrictions which have helped to enhance cross border business relationship.

\subsection{Concept of Small and Medium Scale Business}

History has shown that the concept of small and medium enterprises (SME) was introduced into the development landscape as early as the late 1940s and the main objective was to improve trade and industrialization in the present developed nations (OECD, 2004). The definitions of SME are usually derived in each country, based on the role of SME in the economy, policies and programs designed by particular agencies or institutions empowered to develop SME. In addition, the classification of SME also varies overtime from agencies or developing institutions to another, depending on their policy focus. SMEs can be defined based on certain criteria including, turnover, number of employees, profit, capital employed, available finance, market share and relative size within the industry.

The Central Bank of Nigeria, in its 2005 guideline on Small and Medium Enterprise Investment Scheme (SMEIS), described SME as any enterprise with a maximum asset base of 200million naira (excluding land and working capital) with no lower or upper limit of staff. Using quantitative indices alone to define SMEs have proven unsatisfactory in many respects. This is because such indices are characterized by periodic alterations due to inflation and thus can sometimes be misleading.

\subsubsection{Role of the SME Sub Sector in Economic Development.}

In developing countries, the role of SMEs is more important since SMEs often offer the only realistic prospects for creating additional employment and thus reducing poverty and enhancing the quality of lives (Agbu, 2006).A healthy SME sub-sector is a sine qua non for inclusive and socially sustainable development even though institutions that provide support services where available are often limited in capacity and coverage in developing economies. Exports by SMEs usually range between 30 and 50 percent of total industrial exports in developed and developing countries. In tune with the latest developments in the world economy and the attendant globalization effects, the role of SMEs going forward is bound to be even greater and more pervasive, with a demonstrable impact on the emerging world trading order (Aluko, 2004).

\subsubsection{Challenges of SMES in Nigeria}

The fact that SMEs have not made the desired impact on the Nigerian economy in spite of all the efforts and support of succeeding administrations and governments gives a cause for concern. It underscores the belief that there exists fundamental issues or problems, which confront SMEs but which hitherto have either not been addressed at all or have not been wholesomely tackled.A review of literature reveals indeed the following plethora of problems, which are enormous, fundamental and far-reaching, first of which is the inadequate, inefficient, and at times, non-functional infrastructural facilities, which tend to escalate costs of operation as SMEs are forced to resort to private provisioning of utilities such as road, water, electricity, transportation and communication (Olayode, 2004).

More so, SMEs lack easy access to funding/credits, which can be traceable to the reluctance of banks to extend credit to them owing, among others, to poor and inadequate documentation of business proposals, lack of appropriate and adequate collateral, high cost of administration and management of small loans as well as high interest rates. Furthermore, weakness in organization, 
marketing, information-usage, processing and retrieval, personnel management, accounting records and processing, etc. arising from the dearth of such skills in most SMEs due to inadequate educational and technical background on the part of the SME promoters and their staff (Orunmoluyi, 2000).

\subsubsection{Financing of Small and Medium Scale Enterprises in Nigeria.}

In recent years banks in developed countries have launched a number of initiatives that both improve the profitability of lending SMEs and also provide SMEs with better access to finance and to financial products than that are better failure to their needs. Furthermore, the financing of small scale enterprises goes a long way in determining the strength and success of the business enterprises (Usman, 2009). Adewuyi (2004) said that small scale enterprises are not to remain forever, but the expansion of any business unwisely may be total. The researcher further noted that business expansion should be financial sound, ordinary from earnings or capital contribution of owner's expansion in any case calls for careful advance planning.

Aluko (2001) declared that in order to reduce the high risk cost associated with the financing of small scale enterprises, it is necessary for the institutions to be equipped with staffs that are capable of evaluating pre-investment feasibility studies and surprise projects execution.Adeleke (2002) states that the major problem of many small scale founders is immediate capital problems to start the proposed business; the researcher further explained the source of capital, which are personal savings of the resources in cash original, family, member and friends, financial institutions and the recent innovations in the financing of small business all these depends on the size and large or age of the business determining the strength and success of the business enterprise.

\subsection{Theoretical Framework}

\subsubsection{Theory of Dependency}

Dependency Theory developed in the late 1950s under the guidance of the Director of the United Nations Economic Commission for Latin America, Raul Persist. Prebisch and his colleagues were troubled by the fact that economic growth in the advanced industrialized countries did not necessarily lead to growth in the poorer countries (Agbu, 2006). Indeed, their studies suggested that economic activity in the richer countries often led to serious economic problems in the poorer countries. Such a possibility was not predicted by neoclassical theory, which had assumed that economic growth was beneficial to all (Pareto optimal) even if the benefits were not always equally shared.

Prebisch'sinitial explanation for the phenomenon was very straightforward; poor countries exported primary commodities to the rich countries that then manufactured products out of those commodities and sold them back to the poorer countries. The "Value Added" by manufacturing a usable product always cost more than the primary products used to create those products. Therefore, poorer countries would never be earning enough from their export earnings to pay for their imports (Yusuf, 1994).

\subsection{Empirical Review}

Scholars have conducted researches in the areas of globalization and performance of SMEs in academic world. Elizabeth and James (2006) in the United States of America led to conclusion that all else equal, globalization does not have a significant effect on the profits of white-owned firms but in contrast, the estimated coefficient of all three globalization measures is significant at the 5 percent levels for minority-owned small scale businesses, suggesting that on the average, minorityowned firms that operate in more globalized region earn lower profit.

Onyeaghala and Anele (2014) examined the relationship between globalization and small scale businesses performance and suggested that globalization is strongly and positively related to performance of small scale 
businesses. They found that each dimension (jobs, income or social system) of the small scale businesses performance was positively correlated to globalization. Their finding conform with that of Hitt,et al.,(2001) which state that globalization is the spread of economic innovation around the world and the political and cultural adjustments that accompany this diffusion.

Most of the scholars whose works have been reviewed highlighted the challenges of the small and medium scale businesses as high cost of administration of small loans, high interest rate, and discrimination from banks averse to risk of lending to small borrowers. This study seeks to empirically review the effect of globalization on small and medium scale enterprises in Nigeria. The study will centre on the trade openness as it played an important role in improving service delivery standards in the small and medium scale industry. In pursuance of the objective of the study; attention shall be focused trade openness, bank credit to SMEs and interest rate in business. It is on this basis that the following null hypotheses are formulated:

$\mathrm{H}_{01}$ : Globalization has no overall significant effect on SMEs performance in Nigeria.

$\mathrm{H}_{02}$ : Trade openness does not have significant influence on the performance of SMEs in Nigeria.

$\mathrm{H}_{03}$ : Bank credit has no significant effect on SMEs operations.

$\mathrm{H}_{04}$ : Interest rate has no significant effect on SMEs performance.

\section{METHODOLOGY}

This study adopts an ex post-facto type of descriptive research design. In carrying out this study, the secondary statistics data was used. Data was extracted from CBN bulletin on relevant information which depicts globalization and its effect on SMEs performance in Nigeria.Data collected wereanalysed through regression analysis on the current state of the SMEs sector in this era of global advancement and quality of services provided by SMEs.

The main source of data for this research was from CBN Statistical Bulletin 2014 edition to collect SMEs output, import, export, interest rate. This study adopts co-integration test technique. However, before the application of the technique, the time series characteristics of the variables was examined from 1992 - 2014. In order to capture the full effects of globalization on the performance of small and medium scale enterprises in Nigeria the following specified regression equation model was established and tested:

The econometric specification for model is:

$\mathrm{MCAP} / \mathrm{GDP}_{\mathrm{t}}=\beta_{1}+\beta_{2} \mathrm{BA} / \mathrm{GDP}_{\mathrm{t}}+\beta_{3} \mathrm{M} 2 / \mathrm{GDP}_{\mathrm{t}}+\beta_{4} \mathrm{TS} / \mathrm{GDP}_{\mathrm{t}}+\beta_{5} \mathrm{CPS} / \mathrm{GDP}_{\mathrm{t}}+\beta_{6} \mathrm{INTS}_{\mathrm{t}}+\mathrm{U}$

$\mathrm{SME}=\mathrm{f}(\mathrm{BC} / \mathrm{GDP}, \mathrm{OPEN}+\mathrm{INTR})$

The econometric specification for the model is:

$\mathrm{SME} / \mathrm{GDP}_{\mathrm{t}}=r 0+\gamma 1 \mathrm{BC} / \mathrm{GDP}_{\mathrm{t}}+\gamma 2 \mathrm{OPEN}_{\mathrm{t}}+\gamma 3 \mathrm{INTR}_{\mathrm{t}}+\varepsilon_{\mathrm{t}}$

Where:

$\mathrm{SME} / \mathrm{GDP}_{\mathrm{t}}=$ Output of Small and Medium Scale Enterprises to GDP at time t.

$\mathrm{BC} / \mathrm{GDP}=$ Bank Credit to SMEs to GDP at time t.

OPEN $=$ trade openness $=$ Import+Export/GDP.

INTR $=$ Interest rate

$\gamma 1-\gamma 3=$ Estimated Parameters

$\varepsilon=$ Stochastic error terms

The variables and their relationships are defined thus:

(a) Openness of the economy $(O P N)$ : This is the ratio of trade (imports and exports) to GDP. This is one of the pull factors that influence FDI flows to host countries. 
(b) Bank credit to SMEs (BCSME): This measures the extent of credit creation among the commercial banks to Small and Medium Scale Enterprises in Nigeria within the study period

(c)Interest Rate (INT): This the prime lending rate of the commercial banks to SMEs in Nigeria. It measures the volatility of the loan interest among the small scale business in Nigeria

(d) SME Performance: Output of small and medium scale enterprises: the data used is the contribution of wholesale and retail trade in Nigeria to Gross Domestic Product.

The economic apriori test enables us examine the magnitude and size of the parameters estimate. This evaluation is guided by economic theory to ascertain if the parameter estimate conforms to expectation. Hence it is expected that; $r l>0 ; \gamma 2>0 \gamma 3>0$

Under the statistical test, we will test for the goodness of fit of the individual significance of each regressor using the t-test and finally the significance of the regression models using the f-test.

(i) Goodness of fit test:We shall make use of the coefficient of multiple determinations $\mathrm{R}^{2}$ to find how the variations in the explanatory variable affect the dependent variable.

(ii) Student's t-test: It is used for testing the significance of each variable. We shall make use of $5 \%$ level of significance to determine whether there is significant effect or not.

(iii) The F-test:It will be used for testing the overall significance of the regression models. In order words, it will be used to test the joint impact of the independent variables on the dependent variable.

Econometric test will be used for empirical verification of the model. This will range from testing for serial correlation, normality and heteroscedasticity.

\section{RESULTS}

This section presents the properties of the data used for this study in order to understand the variables as well as the suitability for this study. It will assist in drawing inference under the test of hypothesis.

Table 4.1: The Descriptive Statistics of Variables

\begin{tabular}{|l|c|c|c|c|}
\hline & BC/GDP & INT & OPEN & SME/GDP \\
\hline Mean & 6.173913 & 18.83261 & 20.11520 & 86.69565 \\
\hline Median & 6.000000 & 18.29000 & 16.29836 & 98.00000 \\
\hline Maximum & 23.00000 & 29.80000 & 45.61303 & 147.0000 \\
\hline Minimum & 0.000000 & 13.54000 & 1.777572 & 12.00000 \\
\hline Std. Dev. & 6.176585 & 3.351027 & 13.94636 & 46.56514 \\
\hline Skewness & 0.816156 & 1.614823 & 0.315874 & -0.561106 \\
\hline Kurtosis & 3.294855 & 6.397570 & 1.743448 & 1.997692 \\
\hline Obs & 23 & 23 & 23 & 23 \\
\hline
\end{tabular}

Source: Authors' Computation (2017)

The above table revealed that all the variables have a positive mean value with SME/GDP having the highest value. A further investigation on the table shows that the median of the variables are not too different from the mean value which implies that the variables are symmetry. The maximum and minimum value for the variables ranges from positive to positive for all cases. It was also discovered that SME/GDP also has the highest standard deviation among the variable while the volatility of other are relatively low. It can also be inferred from the table above that the variables are positively skewed, and finally, the table revealed that BC/GDP, OPEN and SME/GDP are platykurtic, while INT is lepokurtic.

Before testing for causality, it is essential to determine the order of integration for each of the variables series. This study conducts the unit root test to determine the order of integration of the series. The Augmented Dickey-Fuller (ADF) tests are reported in Table 3, using Schwarz Info Criterion. 
Table 4.2: Unit root Test

\begin{tabular}{|l|l|l|l|}
\hline Variable & T-Stat & Prob. & Order \\
\hline SME/GDP & -0.97035 & 0.7451 & $\mathrm{I}(1)$ \\
SME/GDP(-1) & -4.07786 & $0.0053^{*}$ & \\
\hline BC/GDP & -1.9801 & 0.2937 & $\mathrm{I}(1)$ \\
BC/GDP(-1) & -3.4056 & $0.0232^{* *}$ & \\
\hline INT & -1.8996 & 0.3285 & $\mathrm{I}(1)$ \\
INT(-1) & -5.4096 & $0.0003^{*}$ & \\
\hline OPEN & -0.9268 & 0.7599 & $\mathrm{I}(1)$ \\
OPEN(-1) & -4.9411 & $0.0008^{*}$ & \\
\hline
\end{tabular}

Source: Authors' Computation (Note: significant level: * 1\%. ** 5\%***10\%)

Table 4.2 above shows that SME/GDP, BC/GDP, INT and OPEN were not stationary at level given their probability value which is not significant. However at first difference SME/GDP, BC/GDP, INT and OPEN became stationary at first difference at $1 \%$ and $5 \%$ significant level. It therefore means that the variables considered in this study are multileveled integrated and integrated of order one, thus a long-run linear combination is suspected amongst them. Therefore a co-integration test is conducted to ascertain if there exist long-run relationships.

\section{Co-integration Test}

This is carried out to determine the existence of long run relationship (co-integration) among the variables and conducted as a pre-test to avoid 'spurious regression' situations. The results are presented in table below.

\section{Table 4.3: Co-integration Test}

The result of the Johansen co-integration test between globalization proxies and SMEs performance in Nigeria from 1992-2014 are given in Table 4.3.

\begin{tabular}{|c|c|l|l|l|l|l|l|}
\hline $\begin{array}{l}\text { Hypothesized } \\
\text { No. of CE(s) }\end{array}$ & Eigenvalue & $\begin{array}{l}\text { Trace } \\
\text { Statistic }\end{array}$ & $\begin{array}{l}\mathbf{0 . 0 5} \\
\text { Critical } \\
\text { Value }\end{array}$ & Prob.** & $\begin{array}{l}\text { Max- } \\
\text { Eigen } \\
\text { Statistic }\end{array}$ & $\begin{array}{l}\text { 0.05 } \\
\text { Critical } \\
\text { Value }\end{array}$ & Prob.** \\
\hline None * & 0.769192 & 70.33069 & 47.85613 & 0.0001 & 29.32340 & 27.58434 & 0.0296 \\
\hline At most 1* & 0.696757 & 41.00728 & 29.79707 & 0.0017 & 23.86445 & 21.13162 & 0.0201 \\
\hline At most 2 & 0.471905 & 17.14284 & 15.49471 & 0.0280 & 12.76959 & 14.26460 & 0.0850 \\
\hline At most 3* & 0.196407 & 4.373254 & 3.841466 & 0.0365 & 4.373254 & 3.841466 & 0.0365 \\
\hline
\end{tabular}

Source: Authors Compilation, (2017)

Trace test indicates 4 cointegratingeqn(s) at the 0.05 level and Max-eigenvalue test indicates 2 cointegratingeqn(s) at the 0.05 level

* denotes rejection of the hypothesis at the 0.05 level

**MacKinnon-Haug-Michelis (1999) p-values

The Trace statistics indicated the existence of 4 co-integrating equations, while the Max-Eigen Value statistics indicated the existence of two co-integrating equation, implying that there exists a long run relationship among the variables. Since the result of the Johansen co-integration test indicated that the variables are co-integrated, the Vector Autoregression model is then employed.

Vector Error Correction (VER) 
The vector error correction model is contained in table 4.4.The coefficient of the ECM is negatively signed but statistically insignificant at probability value at $29.4 \%$. The value shows that the speed of adjustment of long run equilibrium is approximately $43.9 \%$. It therefore suggests that no long run causality exist between globalization and SMEs performance in Nigeria.

Table 4.4: VER

\begin{tabular}{|c|c|c|c|c|}
\hline & Coefficient & Std. Error & t-Statistic & Prob. \\
\hline ECM(-1) & -0.439621 & 0.391104 & -1.124053 & 0.2936 \\
\hline SME GDP(-1) & -0.049155 & 0.556205 & -0.088376 & 0.9318 \\
\hline SME_GDP(-2) & 0.322465 & 0.476706 & 0.676445 & 0.5178 \\
\hline INT(-1) & -15.96111 & 11.59480 & -1.376575 & 0.2059 \\
\hline INT(-2) & -5.415181 & 7.525385 & -0.719589 & 0.4923 \\
\hline BC_GDP(-1) & 16.87692 & 11.82142 & 1.427657 & 0.1912 \\
\hline BC_GDP(-2) & 4.746290 & 8.171879 & 0.580808 & 0.5774 \\
\hline OPEN(-1) & -3.367788 & 3.286187 & -1.024831 & 0.3354 \\
\hline OPEN(-2) & -3.264104 & 3.127450 & -1.043695 & 0.3271 \\
\hline $\mathrm{C}$ & -0.845513 & 9.812357 & -0.086168 & 0.9335 \\
\hline R-squared & 0.510558 & & & \\
\hline Adjusted R-squared & -0.101245 & & & \\
\hline F-statistic & 0.834513 & & & \\
\hline Prob(F-statistic) & 0.613390 & & & \\
\hline Durbin-Watson stat & 1.880289 & & & \\
\hline
\end{tabular}

Note:Significant level: * 1\%. ** 5\%,***10\%

The table above shows the short run equilibrium coefficient of the variables considered in this study. It was revealed that a period lag of interest rate (INT) and openness (OPEN) will bring about a negative effect on SMEs performance while bank credit (BC/GDP) will bring about a positive effect on SMEs performance, however all the variables do not significantly affect SMEs performance. Hence, interest rate, openness, bank credit at this level does not support the performance of SMEs in Nigeria. Conversely, a period lag of interest rate (INT), and bank credit (BC/GDP), have a positive effect on SMEs performance (SME/GDP) while openness (OPEN) have a negative effect on SMEs performance though not statistically significant at acceptable significance level. This suggests that the interest rate and loans from banks will not bring about an increased performance in the SMEs output.

From the above, the R-squared revealed that the explanatory variables explain $51 \%$ of changes in the dependent variable. This implies that about $49 \%$ variation in the independent variable is caused by other factors not considered in this study while The F-statistics shows that the result is not statistically significant as the probability value of F-Statistics is higher than $5 \%$. Thus, this study fails to reject the null hypothesis which states that globalization as no overall significant effect on SMEs performance in Nigeria.

Table 4.5: Post Diagnostic Test

\begin{tabular}{|l|l|l|}
\hline & F-statistic & Prob \\
\hline Normality Test: Jarque-Bera & 1.559885 & 0.4584 \\
\hline Breusch-Godfrey Serial Correlation LM Test: & 0.356876 & 0.7138 \\
\hline Heteroskedasticity Test: Breusch-Pagan-Godfrey & 1.889856 & 0.4009 \\
\hline
\end{tabular}

Source: Authors Compilation, (2017) 
The Breusch-Godfrey Serial Correlation Test was conducted to examined whether the variables are serially correlated, the result in table 4.5 shows that the probability value of F-statistic is not significant at $5 \%(0.71)$ as such we reject the null hypothesis that there is presence of serial correlation among the variables. Also, the normality testwas carried out to check if the residuals are normally distributed. The result of the Jarque-BeraStatistiics suggests that the residuals are averagely distributed given the probability value of $46 \%$. Thus, the diagnostics indicate that the residualsare normally distributed, homoskedastic and seriallyuncorrelated which implies that the result of this study is not spurious and can be relied on for policy making.

\section{SUMMARY AND CONCLUSION}

This empirical work employed cointegration model to investigate the effect of globalization on SMEs performance in Nigeria. To capture the activities of globalization, three proxies were used to capture the activities of globalization; they include interest rate, bank credit and trade openness while on the other hand, output of SMEs to GDP was used to capture SMEs performance covering the period of 1992 to 2014.It is observed that interest rate, bank credit and trade openness do not improve the performance of SMEs output.The overall effect as shown by the F-statistics reveals that the variables considered in this study are not significant in explaining the level of improvement in SMEs output and performance in Nigeria.Hence, the four null hypotheses identified in the study which specified that globalization has no significant effect on SMEs performance, trade openness do not significantly influence SME performance, bank credit has no significant effect on SMEs operation, and interest rate has no significant effect on SMEs performance are all accepted.

The table above shows the short run equilibrium coefficient of the variables considered in this study. It was revealed that a period lag of interest rate (INT) and openness (OPEN) will bring about a negative effect on SMEs performance while bank credit (BC/GDP) will bring about a positive effect on SMEs performance, however all the variables do not significantly affect SMEs performance. Hence, interest rate, openness, bank credit at this level does not support the performance of SMEs in Nigeria. Conversely, a period lag of interest rate (INT), and bank credit (BC/GDP), have a positive effect on SMEs performance (SME/GDP) while openness (OPEN) have a negative effect on SMEs performance though not statistically significant at acceptable significance level. This suggests that the interest rate and loans from banks will not bring about an increased performance in the SMEs output.

As observed from the result, interest rate and trade openness leads to a negative effect on SMEs performance, hence the higher the interest rate, the lower the performance of small scale enterprises within the country, and vice versa. This is also evident in the rate of import and export within the country, as well as its gross domestic product (GDP). Thus in order to enhance SMEs performance within the country, interest rate should be reduced in order to encourage more business to access loans. Furthermore, the finding revealed a positive effect of bank credit on SMEs performance indicating that the higher the bank credits to SMEs, the greater their level of performance. Hence, it is necessary to increase credits and loans to SMEs at a low interest rate in order to enhance their performance, although their level of significance remains insignificant from the above analysis.

Based on the above statement, it is recommended that there is need to restructure as well as strengthen policy to ensure the rapid growth and development of the SMEs sector, more so an active operation of the SMEs Credit Guarantee Scheme should be created to improve credit providers' exposure to longer term debt issued by small firm managers, in such areas as business plan development, feasibility studies, project monitoring and analysis, book keeping and accounting, performance evaluation. 


\section{REFERENCES}

Adeleke (2003).Strengthening small and medium scale entrepreneurship through collaborative partnership projects in Nigeria. International journal of Public - Private Partnering Sheffield University. Central bank of Nigeria, Annual report and statement of accounts various issues.

Adewuyi, A.O. (2004). Can Nigeria benefit from globalization?Constraints, opportunities and challenges.Nigeria economic society.

Agbu (2006).Globalization and the Nigeria's economy.Nigeria Journal of International Affairs, $32(1), 32-45$.

Aluko, S. (2004).Background to globalization and Africa's economic development. Nigeria Economic Society.

Elizabeth, A., \& James, A. F. (2006). The effect of globalization on the performance of Small and medium sized enterprises in the United States: Does owners' race/ethnicity matter? AEA Papers Band Proceedings, 97(2), 368-372.

Hitt, M.A., Ireland, R.D., \&Hoskisson (2001).Strategic management: Competitiveness and globalization.USA, South-West College publishing.

OECD (2004).Promoting entrepreneurship and innovative SMEs in a global economy: Towards a more responsible and inclusive globalization. Report of $2^{\text {nd }}$ OCED Conference of Ministers Responsible for Small and Medium Sized Enterprise (SMEs) in Istanbul, Turkey.

Olayode (2006): Globalization, sustainable development and state capacity in Africa. Nigeria Journal of International Affairs, 32(1), 324-342.

Onyeaghala, O.H.,\& Anele, C.A. (2014). Globalization: effects on small-scale business development in Nigeria.International Journal of Economics, Commerce and Management, 11(5), 1-7.

Orunmoluyi, T. P (2000). Globalization: A millennium challenge for Nigeria banks.The Economics. 4, 31-32.

Sonia, J., \&Rajee, k. (2009).Globalization and its impact on small scale industries in India.PCMA Journal of Business, 1(2), 135-146.

Tendon, Y. (1998).Globalization and African options (part one) in AAPS newsletter, Harare, African Association of Political Science. 3(1), 12-21.

Usman, A. (2009). Globalization and development revisited in the light of Asian Experience.AsiaPacific Development Journal,6(2), 1-21.

Yusuf, J. O. (1994). Globalization and development. Washington, the World Bank. 